\title{
Pretreatment with Fragments of Substance-P or with Cholecystokinin Differentially Affects Recovery from Sub-Total Nigrostriatal 6-Hydroxydopamine Lesion
}

\author{
S. Nikolaus, J.P. Huston, and R.K.W. Schwarting ${ }^{\dagger}$ \\ Institute for Physiological Psychology I, and Center for Biological and Medical Research \\ Heirich-Heine-University of Düsseldorf Universitätsstr. 140225 Düsseldorf, Germany
}

\section{SUMMARY}

The neuropeptide substance $P$ is known to have mnemogenic and reinforcing actions and can exert neurotrophic and regenerative effects in vitro as well as in vivo. Furthermore, our previous work in the rat showed that either pre- or post-lesion treatment with substance $P$ can promote functional recovery in cases of partial nigrostriatal dopamine lesions. Other work has provided evidence that the effects of substance $P$ might be differentially encoded by its $\mathrm{C}$ - and $\mathrm{N}$-terminal fragments. The $\mathrm{C}$-terminal fragment was found to be reinforcing, whereas the mnemogenic as well as neurotrophic properties have been ascribed to the N-terminal sequences. Given these relations, we asked here whether pre-lesion treatment with either a $\mathrm{C}$ - or an $\mathrm{N}$-terminal fragment of substance $P$ might differentially affect the behavioral and neurochemical outcome of nigrostriatal dopamine lesions. Therefore, either substance $\mathbf{P}_{1-7}$ or substance $\mathbf{P}_{5-11}$ $(37 \mathrm{nmol} / \mathrm{kg}$ each) was administered intraperitoneally daily for eight consecutive days before unilateral 6-hydroxy-dopamine lesions of the substantia nigra. Control rats received prelesion treatment with vehicle. Furthermore, we investigated the effects of pre-treatment with

\footnotetext{
${ }^{\dagger}$ Corresponding author:

R. K. W. Schwarting

tel: +211-81-14298; fax: +211-81-12024

e-mail: schwarting@uni-duesseldorf.de
}

Boc-cholecystokinin-4 (0.91 nmol/kg), as we had found an increase in dopamine metabolism in animals that were pre-treated with cholecystokinin-8 in a former study. In accordance with our previous work, drug treatment effects were observed when excluding animals with most severe dopamine lesions: In animals with partial lesions (residual neostriatal dopamine levels of more than $10 \%$ ), lesion-dependent asymmetries in turning behavior were observed in animals that were pre-treated with vehicle-, substance $\mathbf{P}_{1-7}$, or Boc-cholecysto-kinin-4, whereas turning after pre-treatment with substance $P_{5-11}$ was not significantly asymmetrical. Furthermore, the ipsi- and contra-lateral neostriatal dopamine levels did not differ significantly in this group. Moreover, pretreatment with substance $P_{5-11}$ affected dopamine metabolism in the neostriatum and in the venral striatum, as indicated by increased ratios of dihydroxyphenyllic acid to dopamine. The data provide the first evidence that the promotive effects of substance-P treatment in the unilateral dopamine lesion model might be mediated by its $\mathrm{C}$-terminal and might depend on actions on residual dopamine mechanisms.

\section{INTRODUCTION}

The neurotachykinin substance $P$ (SP) enhances reinforcement and learning and promotes functional recovery after lesions of the nigrostriatal dopamine (DA) system (for review 
see $/ 17 /$ ). Furthermore, the evidence shows that these functional effects might be differentially encoded by its $\mathrm{C}$ - and N-terminals: The mnemogenic effect of SP is attributed to its $\mathrm{N}$-terminal amino acid sequences, whereas the reinforcing actions of SP are ascribed to the C-terminal (for review see /17-18/). Additionally, neurochemical studies have shown that the reinforcing effects of SP and its C-terminal are related to enhanced DA activity in the ventral striatum $/ 6-8 /$, whereas the N-terminal fragment $\mathrm{SP}_{1-7}$ had no such effect /6/. Apart from these mnemogenic and reinforcing actions, SP was repeatedly found to exert neurotrophic as well as neuroprotective functions (for example, /19,20, 26,8,39-41/), and in-vitro investigations showed that this capacity might be related to the $\mathrm{N}$-terminal amino acid sequence. Thus, for example, the $\mathrm{N}$-terminal amino acid sequences of $\mathrm{SP}_{1-4}$, and the dipeptides $\mathrm{SP}_{1-2}$ and $\mathrm{SP}_{3-4}$ were found to enhance neuronal growth $/ 24,25,27 /$.

Regarding brain lesions, most behaviorally promotive effects of neurokinins have been found in cases of unilateral 6-hydroxydopamine (6-OHDA) lesions of the nigrostriatal DA system $12,26,28 /$. In this hemiparkinsonian model, unilateral damage of nigrostriatal DA neurons leads to ipsi-lateral asymmetries in turning and scanning, from which the animals can recover over time (reviewed in $/ 10,34,35 /$ ). Our previous work using this lesion model showed that prelesion treatment with $\mathrm{SP}_{1-11}$ promoted behavioral recovery and affected residual DA activity in the neostriatum and in the ventral striatum. In contrast, pretreatment with chole-cystokinin-8 (CCK-8), another neuropeptide that is neuronally associated to the nigrostriatal DA system and known to display neuroprotective properties $/ 13,21,32 /$, did not have behaviorally promotive effects in the 6-OHDA lesion model, and affected residual DA activity only in the neostriatum $/ 28 /$. As treatment with CCK-8 did not affect the behavioral deficits, we concluded that the increased DA metabolism in the ventral striatum, which was induced by the systemic treatment with $\mathrm{SP}_{1-1}$, might be crucial for the reduction of ipsiversive turning behavior. Importantly, these effects were observed in animals with partial but not complete damage of the striatal DA system, which indicates that a critical amount of residual dopamine neurons is necessary for drug treatments to be therapeutically effective $/ 2,26,28 /$ (for further discussion see /35/).

In contrast to the experimental findings with the complete amino acid sequence of SP, no data are available yet in the lesion model regarding the effectiveness of its $\mathrm{C}$ - and $\mathrm{N}$-terminal fragments. Therefore, we investigated the effects of systemic pre-lesion treatments with either a $\mathrm{C}$ - or $\mathrm{N}$ terminal fragment of $\mathrm{SP}\left(\mathrm{SP}_{1-7}, \mathrm{SP}_{5-11}\right)$, or with the Boc-CCK-4 fragment. Rats received eight intraperitoneal injections of either vehicle, $\mathrm{SP}_{1-7}$, $\mathrm{SP}_{5-11}(37 \mathrm{nmol} / \mathrm{kg}$ each$)$, or Boc-CCK-4 (0.91 $\mathrm{nmol} / \mathrm{kg}$ ) before unilateral 6-OHDA lesions of the substantia nigra. Beginning with the first day after lesion, the rats were monitored for asymmetries in turning behavior on every second day for 2 consecutive weeks. Finally, to analyze the degree of DA damage and possible changes in residual DA activity, neostriatal and ventral striatal brain samples were taken. Because previous lesion studies had pointed at the critical role of partial DA lesions, we focused our analysis on animals in which residual neostriatal DA levels on the lesion side were at least $10 \%$ of the intact side. As indicated by the behavioral and neurotrophic studies cited above, differential effects of the peptide fragments might be expected: From reports regarding neurotrophic actions, beneficial behavioral effects might be expected with the $\mathrm{N}$-terminal of SP and with the CCK-4 fragment $124,25,27 /$. In contrast, when considering actions on DA activity, recovery-promoting effects might be more likely with the C-terminal of SP.

\section{METHODS}

\section{Subjects}

Sixty 3-mo-old male Wistar rats (Tierversuchsanlage University of Düsseldorf), weighing 
$220-280 \mathrm{~g}$ at the beginning of the experiment, were housed in groups of 5 animals each under standard laboratory conditions. The animals were maintained under a 12-hour light/dark cycle (lights on at 7:00, lights off at 19:00), and had free access to food and water. Before the experiment, the rats were handled daily for one week.

\section{Drug treatment}

$\mathrm{SP}_{1-7}$ (MG 900.14; Sigma München) and [pGlu5,MePhe8,Sar9]-SP 5-11 (DIME-C7, MG 880.13; Sigma, München) were dissolved in 0.01 $\mathrm{M}$ acetic acid and phosphate buffered saline $(\mathrm{pH}$ 7.4) to final concentrations of $37 \mathrm{nmol} / \mathrm{kg}$. This dose was chosen because it is equimolar to the recovery-promoting dose of the complete sequence of SP $/ 26,28 /$ and because it has been repeatedly shown to be effective in facilitating learning, to have reinforcing effects (for review see $/ 17,18 /$ ), and to increase DA release $/ 6 /$. BocCCK-4 (MG 697.7; Dr. Henklein, Institute of Pharmacology and Toxicology, Humboldt University, Berlin) was dissolved in the same vehicle to a concentration of $0.91 \mathrm{nmol} / \mathrm{kg}$. This dose had been reported to display memoryenhancing effects (for example /14/); furthermore, this dose is equimolar to that of CCK-8 used in our previous lesion study /28/. All injections were made with syringes that had been rinsed with 5 $\mathrm{mM}$ acetic acid. On eight consecutive days, the rats received once daily ip injections of either $\mathrm{SP}_{1-7}(\mathrm{n}=18), \mathrm{SP}_{5-11}(\mathrm{n}=18)$, Boc-CCK-4 $(\mathrm{n}=11)$, or vehicle $(n=13)$. The animals were weighed daily to allow for exact calculation of the injection volume $(1 \mathrm{ml} / \mathrm{kg})$. The injections were administered between 15:00 and 18:00.

\section{6-OHDA lesion}

6-OHDA-hydrobromide (Sigma, München) was dissolved to a concentration of $4 \mathrm{mg} / \mathrm{ml}$ in ice-cold saline (containing $0.2 \mathrm{mg} / \mathrm{ml}$ ascorbic acid). On day 9 , the animals were anesthetized with equithesin $(3 \mathrm{ml} / \mathrm{kg})$ and received unilateral 6-OHDA injections into the substantia nigra under stereotactic surgery (AP $-5.3 \mathrm{~mm}, \mathrm{ML}+$ $2.00 \mathrm{~mm}$, DV $-8.0 \mathrm{~mm}$ ) $/ 29 /$. Therefore, an injection cannula was lowered into the pars compacta of the $\mathrm{SN}$, and $1 \mu \mathrm{l}$ of $6-\mathrm{OHDA}$ was injected by means of an infusion pump (Harvard Apparatus) at a rate of $0.4 \mu \mathrm{l} / \mathrm{min}$. After the infusion, the needle was left in place for another 3 min.

\section{Behavioral testing}

Beginning with the first day after lesion, turning behavior was measured in an open field on every second day for 2 consecutive weeks with a video-image analyzing system (described in detail elsewhere /33/). Behavioral testing (15 min each) was carried out between 10:00 and 15:00 under dim red light. Turning was measured as the number of left or right quarter-turns within a diameter of less than $30 \mathrm{~cm}$.

It has repeatedly been shown that behavioral asymmetries in the present kind of 6-OHDA lesion are most pronounced during the first 3 days after toxin administration; thereafter, the animals, at least those with partial neostriatal DA damage (for review see /34/), can recover to symmetry. Thus, if a treatment acts protectively or promotes behavioral recovery, then such an action should display itself as a lack or reduction of asymmetry on days $1+3$ after lesion. In our previous lesion study with $\mathrm{SP}_{1-11} / 28 /$, the promotive effect of the peptide on behavior was observed at that initial time period, but not thereafter. Therefore, we used the same kind of behavioral analysis here; that is, we pooled behavioral data into blocks consisting of days $1+3$, days $5+7$, days $9+11$, and days $13+15$. A focused statistical analysis was performed on the initial post-lesion period (days 1+3) comparing ipsi- vs. contraversive turning within a treatment group by means of paired t-tests (one-tailed).

\section{Neurochemical and histological analysis}

One week after the last behavioral test, the animals were first anesthetized with equithesin $(3 \mathrm{ml} / \mathrm{kg}$ ) and then decaptitated. The brains were 
dissected, and neostriatal and ventral striatal tissue samples ipsi- and contralateral to the side of the 6-OHDA lesion were analyzed for their concentrations of DA and DOPAC by means of high performance liquid chromatography with electrochemical detection. The remaining caudal parts of the brains were placed into a standard formalin solution and underwent subsequent histological survey regarding cannula placement.

From the tissue concentrations of DA in the ipsilateral and contralateral neostriatum, we computed the residual DA levels on the side of the lesion as percentages of the contralateral side (for example see $/ 11,26,28 /$ ). The values were taken as indices of lesion size. As our former study had shown that pre-lesion treatment with $\mathrm{SP}_{1-11}$ promoted behavioral recovery only in animals whose ipsilateral residual DA levels in the neostriatum were at least $10 \%$ of the respective contralateral side $/ 28$, we excluded all animals with more severe lesions. Finally, we computed the ipsi- and contralateral metabolite/ neurotransmitter ratios (DOPAC/DA). These neurochemical values were compared either (1) within a given group by means of 2-tailed paired t-tests or (2) among all treatment groups by means of one-way analyses of variance (ANOVAs) and post-hoc Duncan's tests for multiple comparisons.

\section{RESULTS}

\section{Exclusion of animals on the basis of histological or neurochemical criteria}

No animal had to be discarded because of inaccurate cannula placement. The post-mortem neurochemical analysis showed that in four animals, who had received pre-lesion treatment with $\mathrm{SP}_{1-7}$, neostriatal DA levels on the side of lesion were less than $10 \%$ of the intact side; the respective numbers of animals were seven in the

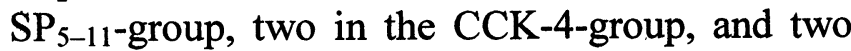
in the vehicle-treated group. After the exclusion of these animals, the group sizes were: $\mathrm{SP}_{1-7}$ $(n=14), S_{5-11}(n=11), C C K-4(n=9)$, and vehicle $(n=11)$.
Behavioral and neurochemical results in animals with partial neostriatal DA lesions

Behavior. The analysis of ipsi- and contralateral turning behavior on post-lesion days $1+3$ yielded ipsiversive asymmetries (paired t-test; one-tailed) in the groups that were pre-operatively treated with $\mathrm{SP}_{1-7}(\mathrm{p}=.006), \mathrm{CCK}-4(\mathrm{p}=.013)$, and vehicle $(\mathrm{p}=.046)$, but a trend for an asymmetry was seen only in the group that had received $\mathrm{SP}_{5-11}(\mathrm{p}=.068$, Table 1).

Neurochemistry. In the neostriatum, ipsilateral DA levels (Table 2) were decreased in the group treated with $\mathrm{SP}_{1-7^{-}}(\mathrm{p}=.003 ; 2$-tailed paired t-test ipsi vs. contra), CCK-4- $(p=.004)$, and vehicle $(\mathrm{p}<.001)$. In contrast, a trend for an asymmetry was seen in animals treated with the C-terminal fragment $\left(\mathrm{SP}_{5-11}, \mathrm{p}=.082\right)$. No between-group differences were found with respect to ipsi(ANOVA, $\mathrm{p}=.522$ ) or contralateral DA levels $(\mathrm{p}=.480)$. Furthermore, no within-group differences between ipsi- and contralateral neostriatal DOPAC/DA ratios were observed (Fig. 1) in any of the four treatment groups (paired t-tests; p-values between .166-.516). Differences between groups did occur, however, because the contralateral DOPAC/ DA ratios in the $\mathrm{SP}_{5-11^{-}}$ treated group exceeded those of all three other treatment groups, whereas the ipsilateral DOPAC/DA ratios in this group were higher than those of animals treated with $\mathrm{SP}_{5-11}$ (Duncan's test, p-values <.05).

In the ventral striatum (Table 2), the ipsilateral DA levels were reduced in the group treated with the N-terminal fragment of SP ( $p=.028$; vs. contra; 2-tailed paired t-test), whereas those in the groups treated with $\mathrm{SP}_{5-11}(\mathrm{p}=.119), \mathrm{CCK}-4$ $(p=.595)$, and vehicle $(p=.226)$ did not differ. Comparing ipsi- or contralateral DA levels between groups did not yield indications for differences (ANOVAs; ipsi: $p=.555$; contra: $\mathrm{p}=.250$ ). No asymmetries occurred between ipsiand contralateral DOPAC/DA ratios (Fig. 2) in any of the four groups (2-tailed paired t-tests; $\mathrm{SP}_{1-7} \mathrm{p}=.094, \mathrm{SP}_{5-11} \mathrm{p}=.995, \mathrm{CCK}-4 \mathrm{p}=.394$, and vehicle $\mathrm{p}=.272$ ). These ratios differed, however, between groups on either side (ANOVAs; ipsi: $p=.014$; contra: $p=.044)$. The post-hoc analysis 
showed that contralateral DOPAC/DA ratios in the $\mathrm{SP}_{5-11}$-treated group exceeded those of the CCK-4- and vehicle-groups (Duncan's test, $\mathrm{p}<.05$ ). Furthermore, the ipsilateral DOPAC/DA ratios of the groups tretaed with SP-fragments were higher than in the CCK-4-treated group (Duncan's test, $\mathrm{p}<.05$ ).

\section{Behavioral and neurochemical results irrespective of actual lesion size}

The preceding analysis showed that pre-lesion treatments with SP-fragments differentially affected he behavioral and neurochemical outcome of the lesion. As expected from our

TABLE 1

Turning behavior in animals with partial lesions

\begin{tabular}{ccllll}
\hline Days after lesion & Turning behavior & SP1-7 & SP5-11 & BocCCK-4 & Vehicle \\
\hline \multirow{2}{*}{$1+3$} & ipsi & $93.4 \pm 14.3^{* *}$ & $112.1 \pm 28.6$ & $105.3 \pm 12.9^{*}$ & $96.1 \pm 15.6^{*}$ \\
& contra & $46.1 \pm 5.6$ & $55.3 \pm 7.5$ & $55.2 \pm 7.9$ & $54.8 \pm 8.8$ \\
\hline \multirow{2}{*}{$5+7$} & ipsi & $81.4 \pm 11.1$ & $95.2 \pm 19.4$ & $116.0 \pm 18.0$ & $81.2 \pm 11.9$ \\
& contra & $77.1 \pm 9.8$ & $79.5 \pm 7.8$ & $90.0 \pm 13.0$ & $80.1 \pm 11.1$ \\
\hline $9+11$ & ipsi & $78.6 \pm 9.9$ & $85.0 \pm 14.8$ & $90.8 \pm 17.2$ & $69.8 \pm 5.8$ \\
& contra & $64.6 \pm 6.4$ & $68.4 \pm 7.1$ & $69.4 \pm 8.5$ & $66.5 \pm 6.9$ \\
\hline $13+15$ & ipsi & $73.6 \pm 9.7$ & $73.4 \pm 11.8$ & $89.3 \pm 16.4$ & $76.8 \pm 11.0$ \\
& contra & $50.9 \pm 6.3$ & $57.5 \pm 6.5$ & $60.3 \pm 8.7$ & $56.4 \pm 6.3$ \\
\hline
\end{tabular}

Turning ipsi- and contraversive to the side of 6-OHDA lesion in rats in which residual neostriatal DA levels exceeded $10 \%$ of the intact side. Data reflect quarter turns (means \pm SEM) measured on post-lesion days $1+3,4+7,9+11$, and $13+15$. Asterisks indicate differences between ipsi- and contraversive turns according to 1 -tailed paired t-tests $\left(* \mathrm{p}<.05 ;{ }^{* *} \mathrm{p}<.01\right)$.

TABLE 2

Dopamine in animals with partial lesions

\begin{tabular}{lllll}
\hline & SP1-7 & SP5-11 & BocCCK-4 & Vehicle \\
\hline Neostriatum & & & & \\
\hline DA ipsi & $3.64 \pm 0.56^{* *}$ & $4.23 \pm 1.03$ & $2.83 \pm 0.83^{* *}$ & $4.54 \pm 0.84^{* * *}$ \\
DA contra & $7.11 \pm 0.97$ & $8.91 \pm 2.55$ & $9.09 \pm 1.75$ & $10.75 \pm 1.46$ \\
\hline Ventral Striatum & & & & \\
\hline DA ipsi & $4.66 \pm 0.72^{*}$ & $4.66 \pm 0.64$ & $4.11 \pm 1.03$ & $6.34 \pm 1.81$ \\
DA contra & $7.55 \pm 0.93$ & $10.08 \pm 3.35$ & $5.11 \pm 1.42$ & $18.35 \pm 9.01$
\end{tabular}

Dopamine (DA) levels in the neostriatum and ventral striatum ipsi- or contralateral to the side 6-OHDA injection. The data, which reflect tissue concentrations ( $\mu \mathrm{g} / \mathrm{g}$ brain tissue, wet weight; mean $\pm \mathrm{SEM}$ ), are taken from rats in which residual neostriatal DA levels exceeded $10 \%$ of the intact side. Asterisks indicate differences between the ipsi- and contralateral side according to 2-tailed paired t-tests $(* \mathrm{p}<.05, * * \mathrm{p}<.01, * * * \mathrm{p}<.001)$. 
previous experiment $/ 28 /$, these findings were obtained in animals with partial neostriatal DA lesions. To test whether the results were dependent on partial lesions, we performed a similar data analysis as above, but now we included also those animals with more severe DA lesions.

When all animals irrespective of their residual neostriatal DA level were analyzed (Table 3), then all groups showed pronounced ipsiversive asymmetries in turning behavior (1-tailed paired t-test; $\mathrm{SP}_{1-7}: \mathrm{p}=.002, \mathrm{SP}_{5-11}: \mathrm{p}=.003, \mathrm{CCK}-4$ : $\mathrm{p}=.004$, vehicle: $\mathrm{p}=.016$ ). Similarly, now all four groups showed pronounced DA depletions (Table 4) in the neostriatum (2-tailed paired t-test; $\mathrm{SP}_{1-7}$ : $\mathrm{p}<.0001, \mathrm{SP}_{5-11}: \mathrm{p}=.002$, CCK-4: $\mathrm{p}=.001$, vehicle: $\mathrm{p}<.00001)$. The neostriatal DA levels did not differ between groups (ANOVA; ipsi: $\mathrm{p}=.581$; contra: $\mathrm{p}=.424)$. The neostriatal DOPAC/DA ratios (Table 4) did not differ either within groups (paired t-tests; $\mathrm{SP}_{1-7}: \mathrm{p}=.472, \mathrm{SP}_{5-11}: \mathrm{p}=.159$, CCK-4: $\mathrm{p}=.066$, vehicle: $\mathrm{p}=.122$ ) or between groups (ANOVAs; ipsi: $\mathrm{p}=.169$; contra: $\mathrm{p}=.184$ ).

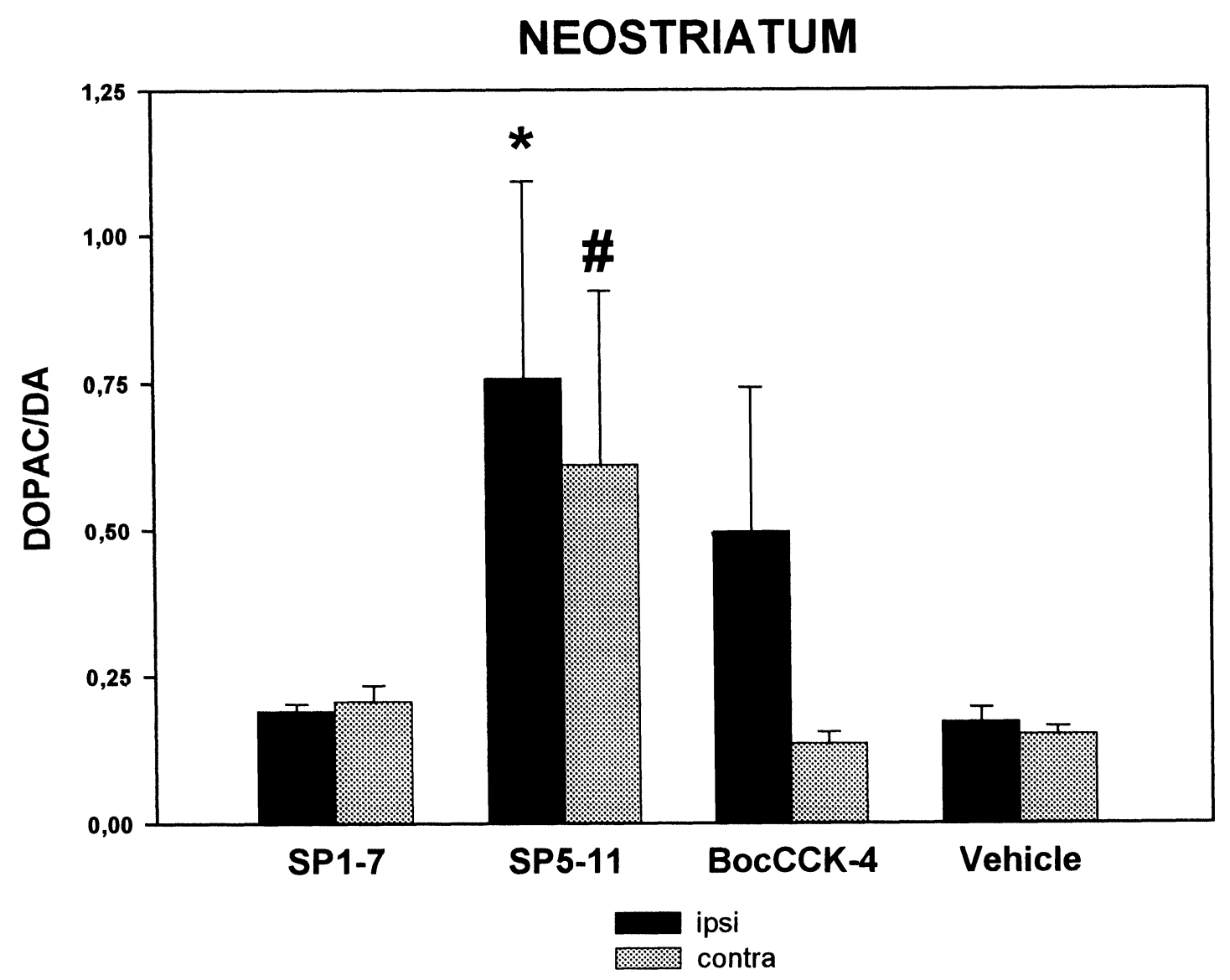

Fig. 1: Ratios of DOPAC/DA (means+SEM) in the neostriatum ipsi- (full bars) and contralateral (gray bars) to the side of 6-OHDA injection. Data were taken from animals with partial neostriatal DA depletions (i.e. neostriatal residual DA levels $>10 \%$ ). Before the 6-OHDA lesion, the animals had been treated systemically for 8 days, either with SP1-7 (14), SP5-11 ( $n=11)$, CCK-4 $(n=9)$ or with vehicle $(n=11)$. Statistical analysis was performed using ANOVAs followed by Duncan's test: * indicates a difference $(p<.05)$ in comparison with the SP1-7 group; \# indicates differences $(p<.05)$ in comparison with vehicle, SP1-7, and CCK-4. 
In the ventral striatum (Table 4), ipsilateral DA levels were reduced in the group pre-treated with the N-terminal of SP (2-tailed paired t-test, ipsi vs. contra, $\mathrm{p}=.011$ ). For $\mathrm{SP}_{5-11}, \mathrm{CCK}-4$, and vehicle, the respective $\mathrm{p}$-values were $.069, .174$, and .210. The DA levels did not differ between groups (ANOVAs; ipsi: $\mathrm{p}=.445$; contra: $\mathrm{p}=.301$ ). The ipsi- and contralateral DOPAC/DA ratios (Table 4) were balanced within all four groups (paired t-tests; $\mathrm{SP}_{1-7}: \mathrm{p}=.612, \mathrm{SP}_{5-11}: \mathrm{p}=.368$, CCK-4: $p=.289$, vehicle: $p=.700$ ). Between-group comparisons did not indicate substantial differences on the contra-lateral side (ANOVA; $\mathrm{p}=.221$ ), in contrast to ipsilateral DOPAC/DA ratios (ANOVA; $\mathrm{p}=.050$ ), which were higher in the $\mathrm{SP}_{1-7}$ than in the $\mathrm{CCK}-4$-treated group (Duncan's test, $\mathrm{p}<.05$ ).

\section{VENTRAL STRIATUM}

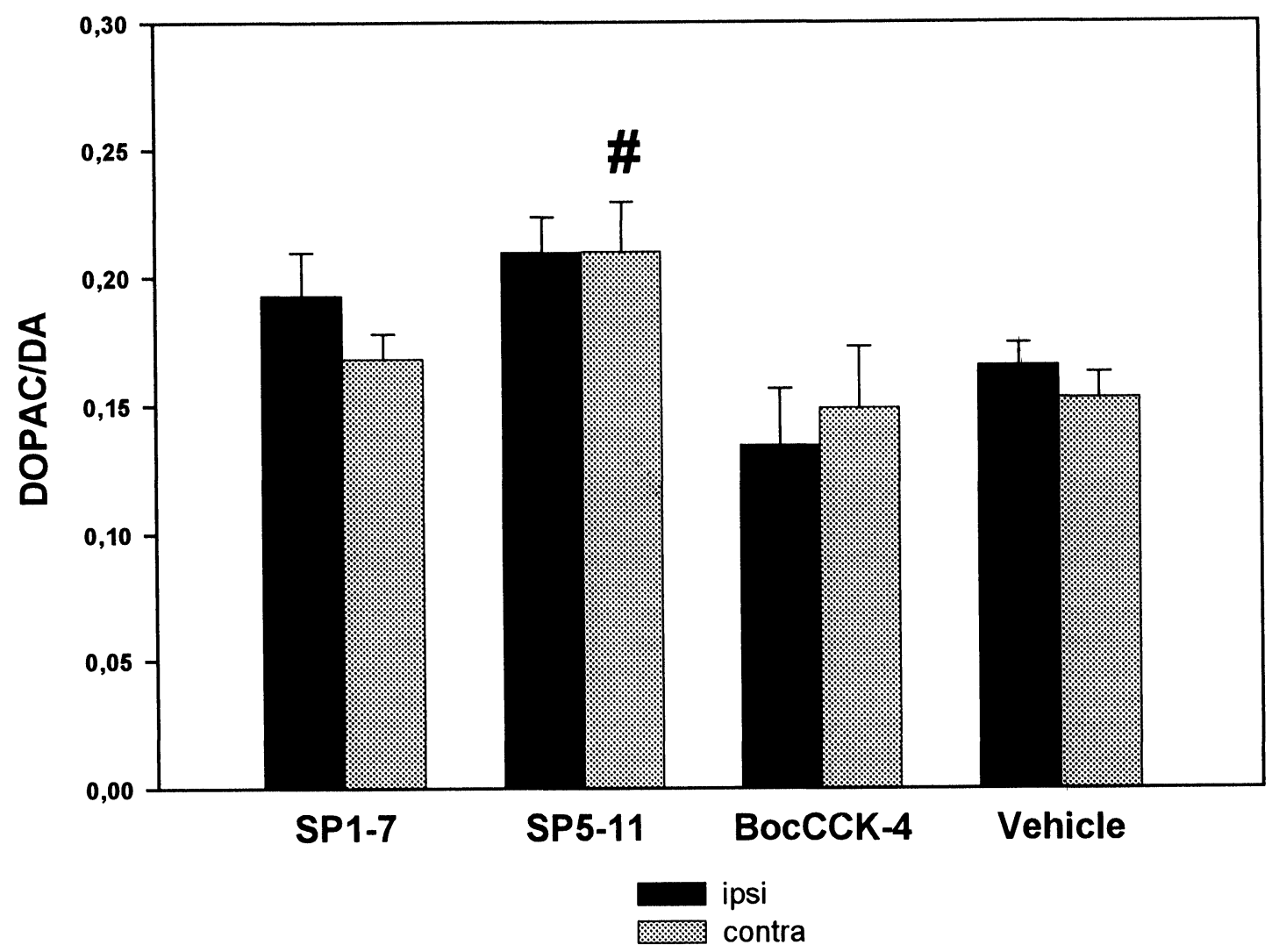

Fig. 2: Ratios of DOPAC/DA (means+SEM) in the ventral striatum ipsi- (full bars) and contralateral (gray bars) to the side of 6-OHDA injection. Data were taken from animals with partial neostriatal DA depletions (i.e. neostriatal residual DA levels $>10 \%$ ). Before the 6-OHDA lesion, the animals had been treated systemically for 8 days, either with $\mathrm{SP}_{1-7}(14), \mathrm{SP}_{5-11}(n=11), \mathrm{CCK}-4(\mathrm{n}=9)$ or with vehicle $(n=11)$. Statistical analysis was performed using ANOVAs followed by Duncan's test: \# indicates a difference $(p<.05)$ in comparison with vehicle, and CCK-4. 
TABLE 3

Turning behavior irrespective of lesion size

\begin{tabular}{llllll}
\hline Days & & SP1-7 & SP5-11 & BocCCK-4 & Vehicle \\
\hline $1+3$ & ipsi & $100.1 \pm 13.8^{* *}$ & $130.4 \pm 21.6^{* *}$ & $116.2 \pm 15.3 * *$ & $108.5 \pm 17.2 *$ \\
& contra & $42.8 \pm 5.5$ & $45.1 \pm 6.2$ & $47.2 \pm 8.4$ & $50.5 \pm 8.2$ \\
\hline $5+7$ & ipsi & $83.9 \pm 9.9$ & $99.4 \pm 13.2$ & $126.3 \pm 20.3$ & $89.5 \pm 12.4$ \\
& contra & $73.1 \pm 8.3$ & $72.3 \pm 7.7$ & $77.6 \pm 13.5$ & $76.3 \pm 10.6$ \\
\hline $9+11$ & ipsi & $76.7 \pm 8.3$ & $85.6 \pm 9.7$ & $90.9 \pm 15.0$ & $79.4 \pm 9.1$ \\
& contra & $60.7 \pm 5.7$ & $62.3 \pm 5.8$ & $62.5 \pm 8.7$ & $63.8 \pm 6.8$ \\
\hline $13+15$ & ipsi & $72.8 \pm 8.3$ & $71.7 \pm 7.2$ & $90.7 \pm 15.1$ & $92.1 \pm 16.2$ \\
& contra & $48.6 \pm 5.3$ & $49.4 \pm 5.4$ & $55.1 \pm 8.1$ & $52.8 \pm 6.0$ \\
\hline
\end{tabular}

Turning ipsi- and contraversive to the side of 6-OHDA lesion irrespective of neostriatal lesion size. Data reflect quarter turns (means \pm SEM) measured on post-lesion days $1+3,4+7,9+11$, and $13+15$. Asterisks indicate differences between ipsi- and contraversive turns according to 1 -tailed paired t-tests $(* \mathrm{p}<.05 ; * * \mathrm{p}<.01)$.

TABLE 4

Dopamine and DOPAC/DA ratios irrespective of lesion size

\begin{tabular}{|c|c|c|c|c|c|}
\hline & & SP1-7 & SP5-11 & BocCCK-4 & Vehicle \\
\hline \multicolumn{6}{|c|}{ Neostriatum } \\
\hline \multirow[t]{2}{*}{ DA } & ipsi & $3.11 \pm 0.54 * * *$ & $2.82 \pm .76^{* *}$ & $2.47 \pm 0.72 * *$ & $3.94 \pm 0.82 * * *$ \\
\hline & contra & $7.11 \pm 0.54$ & $9.80 \pm 1.86$ & $9.40 \pm 1.54$ & $10.73 \pm 1.23$ \\
\hline \multicolumn{6}{|c|}{ DOPAC/DA } \\
\hline & ipsi & $187 \pm 0.019$ & $4.685 \pm 2.881$ & $0.601 \pm 0.232$ & $0.180 \pm 0.022$ \\
\hline & contra & $0.206 \pm 0.022$ & $0.439 \pm 0.184$ & $0.134 \pm 0.016$ & $0.147 \pm 0.012$ \\
\hline \multicolumn{6}{|c|}{ Ventral Striatum } \\
\hline \multirow[t]{2}{*}{ DA } & ipsi & $4.44 \pm 0.45^{*}$ & $4.17 \pm 0.53$ & $3.75 \pm 0.91$ & $5.60 \pm 1.60$ \\
\hline & contra & $9.36 \pm 1.85$ & $8.13 \pm 2.17$ & $6.95 \pm 1.73$ & $16.05 \pm 7.72$ \\
\hline \multicolumn{6}{|c|}{ DOPAC/DA } \\
\hline & ipsi & $0.180 \pm 0.012$ & $0.176 \pm 0.017$ & $0.128 \pm 0.023$ & $0.168 \pm 0.012$ \\
\hline & contra & $0.174 \pm 0.007$ & $0.189 \pm 0.014$ & $0.151 \pm 0.019$ & $0.162 \pm 0.011$ \\
\hline
\end{tabular}

Dopamine (DA; $\mu \mathrm{g} / \mathrm{g}$ brain tissue, wet weight; mean \pm SEM) levels and DOPAC/DA ratios in the neostriatum and ventral striatum ipsi- or contralateral to the side 6-OHDA injection. The data are taken from all rats irrespective of neostriatal lesion size. Asterisks indicate differences between the ipsi- and contralateral side according to 2-tailed paired t-tests $\left({ }^{*} \mathrm{p}<.05\right.$, $\left.{ }^{* *} \mathrm{p}<.01,{ }^{* * *} \mathrm{p}<.001\right)$. 


\section{DISCUSSION}

This experiment provides the first evidence that systemic pre-treatments of rats with either the C- or the N-terminal fragments of SP can differentially affect the outcome of unilateral, nigrostriatal DA lesions, given that the lesions are partial. Thus, only after excluding animals in which neostriatal DA levels on the side of lesion fell below $10 \%$ of the contralateral side, did we observe that the group pre-treated with $\mathrm{SP}_{5-11}$ did not show a significant asymmetry in turning behavior, whereas the other three groups did so. In parallel, neostriatal DA levels on the side of 6-OHDA injection were not significantly decreased in the group pre-treated with $\mathrm{SP}_{5-11}$, in contrast to the groups pre-treated with $\mathrm{SP}_{1-7}$, CCK-4, or vehicle, in which the ipsilateral DA levels were lower than those of the contralateral side. Finally, the group treated with $\mathrm{SP}_{5-11}$ showed several indications for changes in striatal DA activity: The contralateral neostriatal DOPAC/DA ratio exceeded those of the other treatment groups, and those of the N-terminal group on the ipsilateral side. Also, in the ventral striatum, the animals that had received the C-terminal fragment of SP displayed higher contralateral DOPAC/DA ratios when compared with the groups treated with the CCK-fragment or vehicle. Thus, this experiment generally supports previous findings that SP can be behaviorally promotive in case of nigrostriatal DA damage, and that this effect may be related to changes in DA mechanisms $12,26,28 /$. Furthermore, the present study indicates that these effects may be linked to the C-terminal, but not to the $\mathrm{N}$-terminal, of the peptide.

\section{The CCK-fragment}

In contrast to the C-terminal fragment of SP, pre-lesion treatment with CCK-4 had no effect on turning behavior, neither in the subsample of animals with partial lesions nor when also including those with more severe lesions. This result extends our previous findings with CCK-8 128/, wherein pre-lesion treatment did not promote functional recovery. Treatment with CCK-8 affected neostriatal DA activity (namely, increased DOPAC/DA ratios), but had no effect in the ventral striatum $/ 28 /$, and we assumed that this lack of effect in the ventral striatum was related to that on behavioral recovery. CCK-4 treatment had no DA-activating effect on either structure. Thus, one may conclude either that CCK-4 did not reach the brain in sufficient amounts to be neurochemically effective or that this shorter amino acid sequence of CCK has no (or no lasting) effect on the regulation of striatal DA activity. Altogether, the results of this and the preceding study $/ 28 /$ provide no evidence that systemic pre-lesion treatment with $\mathrm{CCK}$, a peptide that is closely related to DA neurons in the brain, has beneficial effect in the case of nigrostriatal DA damage.

\section{The SP-fragments}

Our previous studies had shown that either pre- or post-lesion treatment with SP can be behaviorally promotive in the partial DA lesion model because systemic peptide treatments promoted functional recovery or even prevented deficits from occurring $/ 26,28 /$. The results of the present experiment indicate that these effects may be related to the C-terminal of the peptide because only the group treated with $\mathrm{SP}_{5-11}$ showed promotive effects on turning behavior.

Similar to our previous study with $\mathrm{SP}_{1-11} / 28$, the behavioral effects of $\mathrm{SP}_{5-11}$ could be measured only when the animals with the most severe lesions were discarded from evaluation. Evidently, a minimum number of intact nigrostriatal neurons is necessary for $\mathrm{SP}_{5-11}$, as well as for $\mathrm{SP}_{1-11}$, to exert their effects. Similar conclusions were also drawn in a previous study with a neurokinin-3 agonist $/ 2 /$ and in other studies in which the promotive effects of growth factors were investigated (for example $/ 5,36,37 /$ ). Altogether, these findings point to the importance of studying partial, in contrast to total, striatal DA depletions when investigating the effectiveness of treatments in animal models of striatal DA damage (see also /31/). 
Apart from behavior, pre-lesion treatment with $\mathrm{SP}_{5-11}$ affected striatal DA activity: After excluding animals with more severe lesions (i.e. residual DA levels $<10 \%$ ), ipsi- and contralateral neostriatal DA levels no longer differed significantly in this group. Furthermore, the

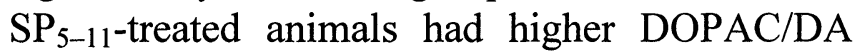
ratios in the neo- and ventral striatum. When discussing the possible mechanisms of these actions, various aspects must be considered: As $\mathrm{SP}_{5-11}$, which can penetrate the blood-brainbarrier $/ 1 /$, was administered intraperitoneally, this fragment might have acted peripherally and/or centrally. For example, SP plays a role in the gastro-intestinal and immune systems, renal function, blood flow, and pain perception (for example, $130,31 \%$. Thus, $\mathrm{SP}_{5-11}$ might have indirectly affected processes in the central nervous system via actions on these mechanisms. Alternatively, it should be considered that intraperitoneal as well as central injections of SP and $\mathrm{SP}_{5-11}$ can enhance striatal $\mathrm{DA}$, and that these effects can be rather long lasting /6-8,32/. Such DAergic effects were not shared by the $\mathrm{N}$ terminal $/ 6 \%$. As compensatory changes in DAergic mechanisms are thought to play a critical role for functional recovery after nigro-striatal DA damage (for review see $/ 34,35 /$ ), one can hypothesize that the DAergic actions of $\mathrm{SP}_{5-11}$ were critical for its behavioral effect, and that the previous behavioral and neurochemical findings observed with SP $/ 26,28$ / were mediated by its C-terminal fragment. Furthermore, it can be concluded that the N-terminal, which can be neurotrophic in-vitro $/ 24,25,27 /$, appears to be ineffective, at least in the case of treatments preceding 6-OHDA lesions. Thus, one might assume that in the 6-OHDA model, neurotrophic actions of SP, which have been suggested to be critical in neurodegenerative diseases like Alzheimer's or Parkinson's disease $/ 3,4 /$, come into play once the lesion has been placed, and that the N-terminal might therefore become effective when given post- rather than pre-lesion.

In our previous studies, we found no evidence for a protective action of SP because the degree of DA damage was not affected by either pre- or post-lesion treatment $/ 26,28 /$. Therefore, one may assume that the present lack of significant asymmetry in neostriatal DA levels after pretreatment with $\mathrm{SP}_{5-11}$ reflects compensatory DA mechanisms rather than a protective action against damage. As the indications of increased DA activity were observed in both hemispheres, one can furthermore assume that DAergic mechanisms on the intact (contralateral) side had played a role. Interestingly, evidence has been presented for compensatory increases in the intact substantia nigra, which also sends crossed efferents to the damaged neostriatum /16/. Changes in these crossed connections from the intact side were shown to be related to recovery from unilateral 6-OHDA studies /16/. Thus, one can speculate that the increased contralateral DOPAC/ DA ratios observed here in the $\mathrm{SP}_{5-11}$ treated group might reflect such a compensatory increase in the activity of the intact substantia nigra.

In this experiment with $\mathrm{SP}_{5-11}$ and in the preceding experiment with $\mathrm{SP}_{1-11} / 28 /$, changes in DA activity were observed not only in the neostriatum but also in the ventral striatum. Interestingly, DAergic mechanisms in the ventral striatum, especially its nucleus accumbens, have been related not only to compensatory mechanisms after 6-OHDA lesions (for review see /34/) but also to mechanisms of reinforcement $/ 11,23 /$. Thus, drugs having reinforcing effects are known to increase the release of DA in the nucleus accumbens /9/. Such reinforcing and neurochemical actions are shared by SP and its $\mathrm{C}$-terminal fragment, but not by the $\mathrm{N}$-terminal /6-8,17,18/. Therefore, one can speculate that DA mechanisms that are critical for reinforcement also play a role in mechanisms of functional recovery after nigrostriatal DA lesions.

When discussing all these possible actions, however, one should consider that all drug treatments in the present experiment had been terminated before the lesions were made, which leads to the following considerations: First, one might assume that treatment with $\mathrm{SP}_{5-11}$ had direct, long-term consequences that outlasted the period of treatment. Behavioral evidence for such 
an effect was obtained in a previous study in old rats, in which the beneficial effect on water maze performance was still observed one week after terminating peripheral treatment with SP /15/. Alternatively, it is possible that the present findings in the lesion model were determined, or at least affected, by mechanisms of drug withdrawal. Compensatory changes in response to prolonged drug treatments and/or their withdrawal are especially likely in case of drugs that act as reinforcers and that increase ventral striatal DA release (for review see /9,23/). Thus, one might assume, for example, that the DAergic changes observed here after $\mathrm{SP}_{5-11}$, and previously after $\mathrm{SP}_{1-11} / 26 /$, actually reflect compensatory responses to drug treatment and/or withdrawal rather than compensatory responses to the lesion. If so, it might be possible that such drugdependent compensatory responses provide the prerequisites for compensation for functional recovery. Furthermore, it might be interesting to test whether pre-lesion treatment with (and thus withdrawal from) other reinforcing and DAreleasing drugs (like opiates, or stimulants) affect recovery in this partial DA lesion model.

Altogether, the present study provides evidence that systemic pre-lesion treatment with $\mathrm{SP}_{5-11}$, but not with $\mathrm{SP}_{1-7}$ or $\mathrm{CCK}-4$, can have promotive behavioral effects in the case of partial unilateral DA lesions. The effects were paralleled by changes in neostriatal and ventral striatal DA activity, which may reflect promotive influences on compensatory DAergic responses after lesion, and/or interactions with compensations after withdrawal from prolonged peptide treatment.

\section{ACKNOWLEDGMENTS}

This work was supported by grant $\mathrm{Hu}$ 306/132 from the Deutsche Forschungsgemeinschaft, and by the Center for Biological and Medical Research at the University of Düsseldorf. R.K.W. Schwarting is a Heisenberg fellow of the Deutsche Forschungsgemeinschaft.

\section{REFERENCES}

Banks WA, Kastin AJ. Saturable transport of peptides across the blood-brain barrier. Life Sciences 1987; 41: 1319-1338.

Bannon MJ, Brownschidle LA, Tian Y, Whitty CJ, Poosch MS, D'sa C, Moody CA. Neurokinin-3 receptors modulate dopamine cell function and alter the effects of 6-hydroxydopamine. Brain Res 1995; 695: 19-24.

Barker R. Substance P and Parkinson's disease: A causal relationship? J Theor Biol 1986; 120: 353-362.

Barker R. Substance P. and neurodegenerative disorders. A speculative review. Neuropeptides 1991; 20: 7378.

Bea AJ, Elde R, Oellig C, Cao Y, Pettersson RF, Hökfelt T. Acidic and basic fibroblast growth factors are present in and produce effects upon mesencephalic dopamine neurons. In: Fuxe K, Agnati LF, Bjelke B, Ottoson D, eds., Trophic Regulation of the Basal Ganglia. Pergamon Press, 1994; 267-284.

Boix F, Huston JP, Schwarting RKW. The C-terminal fragment of substance $P$ enhances dopamine release in nucleus accumbens but not in the neostriatum in freely moving rats. Brain Res 1992a; 592: 181-186.

Boix F, Mattioli R, Adams F, Huston JP, Schwarting RKW. Effects of substance $P$ on extracellular dopamine in neostriatum and nucleus accumbens. Eur J Pharmacol 1992b; 216: 103-107.

Boix F, Sandor P, Nogueira PJC, Huston JP, Schwarting RKW. Relationship between dopamine release in nucleus accumbens and place preference induced by substance $P$ injected into the nucleus basalis magnocellularis region. Neuroscience 1995; 64: 1045-1055.

DiChiara G, Imperato A, Mulas A. Preferential stimulation of dopamine release in the mesolimbic system: a common feature of drugs of abuse. In: Sandler M, Feuerstein C, Scatton B, eds, Neurotransmitter Interactions in the Basal Ganglia. New York: Raven Press, 1987; 171-182.

Emmi A, Rajabi H, Stewart J. Behavioral and neurochemical recovery from partial 6-hydroxydopamine lesions of the substantia nigra is blocked by daily treatment with glutamate receptor antagonists MK-801 and CPP. J Neurosci 1994; 16: 5216-5224.

Fibiger HC, Phillips AG. Mesocorticolimbic dopamine systems and reward. Ann NY Acad Sci 1988; 537: 206-215.

Fornaguera J, Carey RJ, Huston JP, Schwarting RKW. Behavioral asymmetries and recovery in rats with different degrees of unilateral striatal dopamine depletion. Brain Res 1994; 664: 178. 
Fujisawa M, Miyamoto O, Itano T, Tokuda M, Matsui H, Nagao S, Negi T, Hatase O. Ceruletide suppresses rotational behavior in lesioned rats via CCKA receptors. Europ J Pharmacol 1993; 238: 127-130.

Gerhardt P, Voits M, Fink H, Huston JP. Evidence for mnemotropic action of cholecystokinin fragments Boc-CCK-4 and CCK-8S. Peptides 1994; 15: 689697.

Hasenöhrl RU, Frisch C, Nikolaus S, Huston JP. Chronic administration of neurokinin SP improves maze performance in aged Rattus norvegicus. Behav Neural Biol 1994; 62: 110-120.

Huston JP, Morgan S, Steiner H. Plasticity in crossed efferents to the substantia nigra as related to behavioral reorganization. In: Schneider JS, Lidsky TI, eds., Basal Ganglia and Behavior: Sensory Aspects of Motor Functioning. Bern: Huber, 1987, 89-102.

Huston JP, Hasenöhrl RU, Boix F, Gerhardt P, Schwarting RKW. Sequence-specific effects of neurokinin substance $P$ on memory, reinforce-ment, and brain dopamine activity. Psycho-pharmacology 1993; 112: 147-162.

Huston JP, Hasenöhrl RU. The role of neuro-peptides in learning: focus on the neurokinin substance P. Behav Brain Res 1995; 66: 117-127.

Jonsson G, Hallmann $H$. Substance $P$ counteracts neurotoxic damage on norepine-phrine neurons in rat brain during ontogeny. Science 1982a; 215: 75-77.

Jonsson G, Hallman $H$. Substance $P$ modifies the 6hydroxydopamine induced alteration of post-natal development of central noradrenal-ine neurons. Neuroscience 1982b; 7: 2909-2918.

Katsuura G, Shinohara S, Shintaku H, Eigyo M, Matusushita A. Protective effect of CCK-8 and ceruletide on glutamate-induced neuronal cell death in rat neuron cultures: possible involvement of CCKB receptors. Neurosci Lett 1991; 132: 159-162.

Khan S, Brooks N, Whelpton R, Michael-Titus AT. Substance P-(1-7) and substance P-(5-11) locally modulate dopamine release in rat striatum. Eur $\mathrm{J}$ Pharmacol 1995; 282: 229-233.

Koob GF, Bloom FE. Cellular and molecular mechanisms of drug dependence. Science 1988; 242: 715-723.

Lindner G, Grosse G, Oehme P, Jentzsch KD, Neubert K. Über die Wirkung von Substanz P (SP) und SPTeilsequenzen auf das Nervenfaser-wachstum in der Gewebekultur. Z mikrosk anat Forsch 1982; 96: 643655.

Lindner G, Gadewa S. Über die Wirkung von N- und Cterminalen Sequenzen der Substanz $P$ auf nichtneuronale Zellen in vitro (Nervenge-webekultur). $\mathrm{Z}$ mikrosk anat Forsch 1984; 98: 107-118.

Mattioli R, Schwarting RKW, Huston JP. Recovery from unilateral 6-hydroxydopamine lesion of substantia nigra promoted by the neurotachykinin substance P111. Neuroscience 1992; 48: 595-605.

Narumi S, Maki Y. Stimulatory effects of substance P on neurite extension and cyclic AMP levels in cultured neuroblastoma cells. J Neurochem 1978; 30: 13211326.

Nikolaus S, Huston JP, Körber B, Thiel C, Schwarting RKW. Pre-treatment with neurokinin substance $P$ but not with cholecystokinin-8S can alleviate functional deficits of partial nigrostriatal 6-hydroxydopamine lesion. Peptides 1997; 18:

Paxinos G, Watson C. The rat brain in stereotaxic coordinates. Sidney: Academic Press, 1986.

Payan DG.The role of neuropeptides in inflam-mation. In: Gallin JI, Goldstein IM, Snyderman R, eds, Inflammation: Basic Principles and Clinical Correlates. New York: Raven Press, 1992; 177.

Pernow B. Substance P. Pharmacol Rev 1983; 35: 85141.

Reid MS, Herrera-Marschitz M, Hökfelt T, Lindefors N, Persson $H$, Ungerstedt $U$. Striato-nigral GABA, dynorphin, substance $P$ and neurokinin A modulation of nigrostriatal dopa-mine release: evidence for direct regulatory mechanisms. Exp Brain Res 1990; 82: 293-303.

Schwarting RKW, Goldenberg R, Steiner H, Fornaguera J, Huston JP. A video-image analyzing system for open-field behavior in the rat focusing on behavioral asymmetries. J Neurosci Meth 1993; 49: 199-210.

Schwarting RKW, Huston JP. Unilateral 6-hydroxydopamine lesions of mesostriatal dopamine neurons and their physiological sequelae. Progr Neurobiol 1996a; 49: 215-266.

Schwarting RKW, Huston JP. The unilateral 6-hydroxydopamine lesion model in behavioral brain research. Analysis of functional deficits, recovery and treatments. Prog Neurobiol 1996b; 50: 275-331.

Spina MB, Squinto SP, Miller J, Lindsay RM, Hyman C. Brain-derived neurotrophic factor protects dopamine neurons against 6-hydroxy-dopamine and N-methyl4-phenylpyridinium ion toxicity: Involvement of the glutathione system. J Neurochem 1992; 59: 99-105.

Stromberg I, Herrera-Marschitz M, Ungerstedt U, Ebendal T, Olson L. Chronic implants of chromaffin tissue into the dopamine-denervated striatum. Effects of NGF on graft survival, fiber growth and rotational behavior. Exp Brain Res 1985; 60: 335-349.

Tamura Y, Sato Y, Akaike A, Shiomi, H. Mechanisms of cholecystokinin-induced pro-tection of cultured cortical neurons against N-methyl-D-aspartate receptor-mediated gluta-mate cytotoxicity. Brain Res 1992; 592: 317-325.

White DM, Ehrhard P, Hardung M, Meyer KD, Zimmermann M, Otten U. Substance P modulates the release of locally synthesized nerve growth factor 
from rat saphenous nerve neuroma. NaunynSchmiedeberg's Arch Pharmacol 1987; 336: 587590.

Whitty CJ, Kapatos G, Bannon MJ. Neurotrophic effects of substance $\mathrm{P}$ on hippocampal neurons in vitro.
Neurosci Lett 1993; 164: 141-144.

Yankner BA, Duffy LK, Kirschner DA. Neurotrophic and neurotoxic effects of amyloid beta protein: reversal by tachykinin neuropeptides. Science 1990; 250: 279-282. 

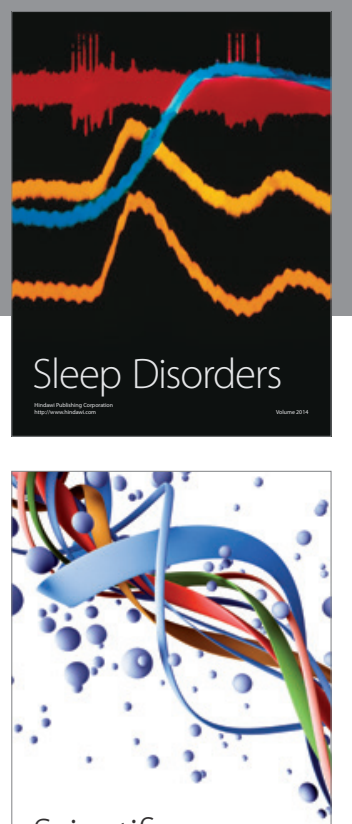

Scientifica
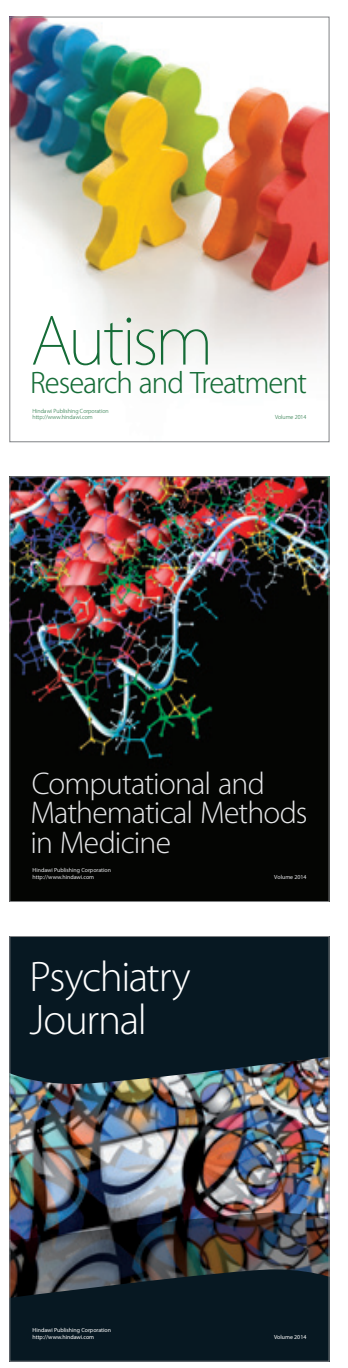
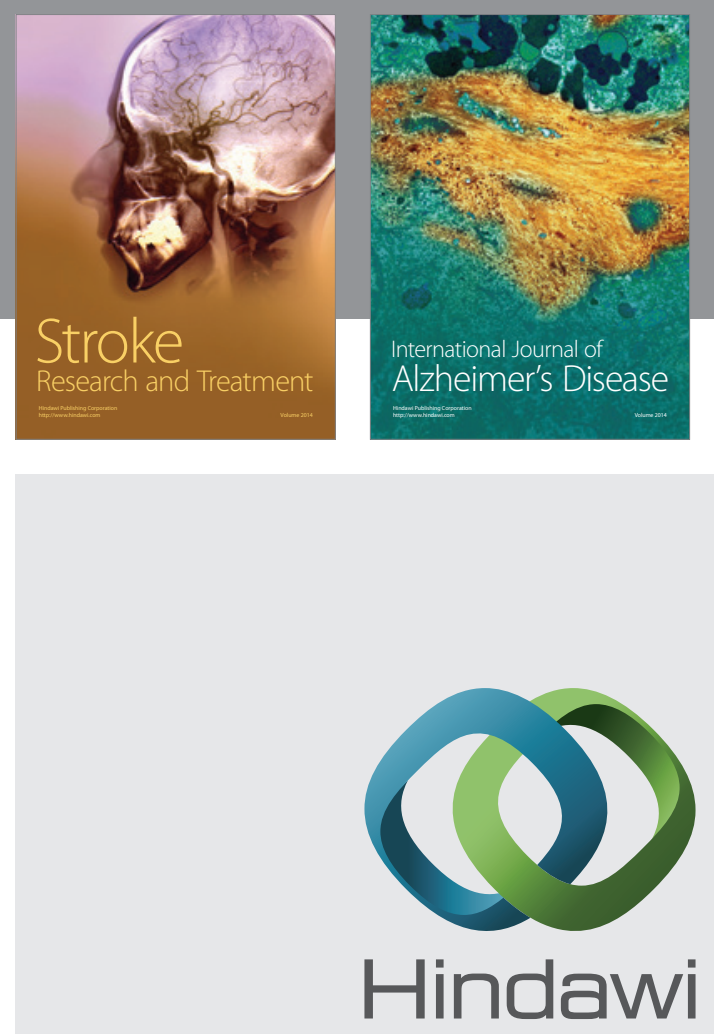

Submit your manuscripts at

http://www.hindawi.com
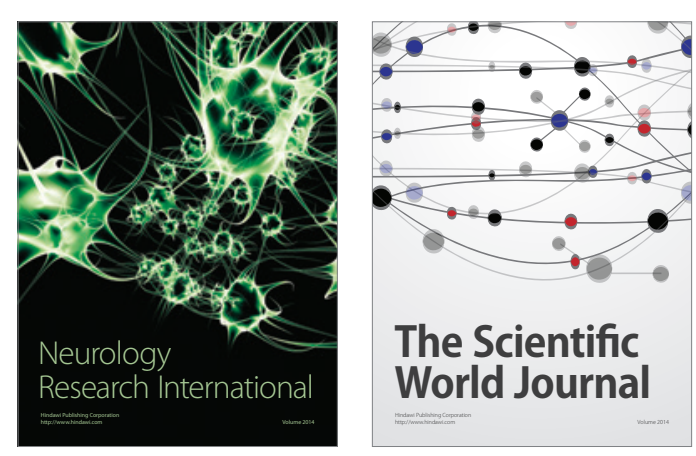

The Scientific World Journal

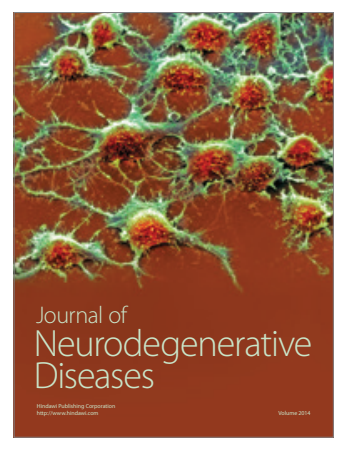

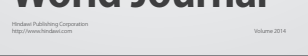

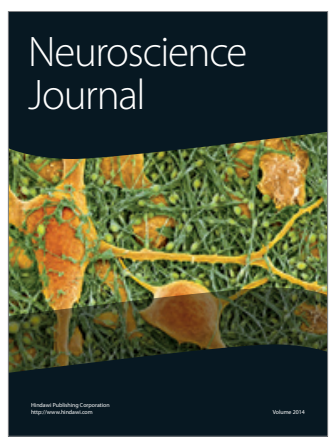

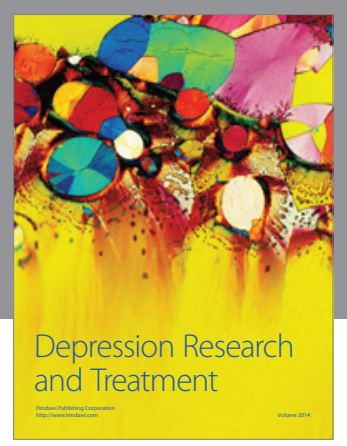
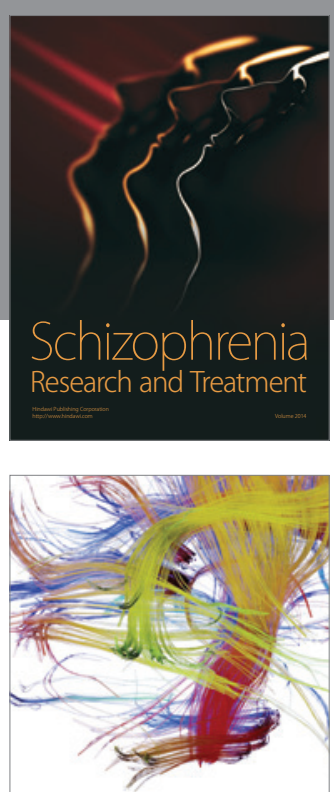

Brain Science

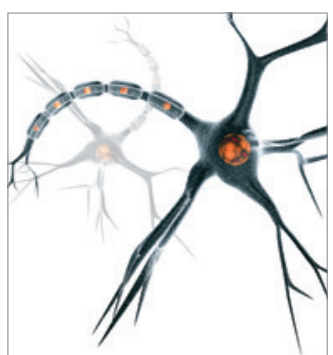

Neural Plasticity
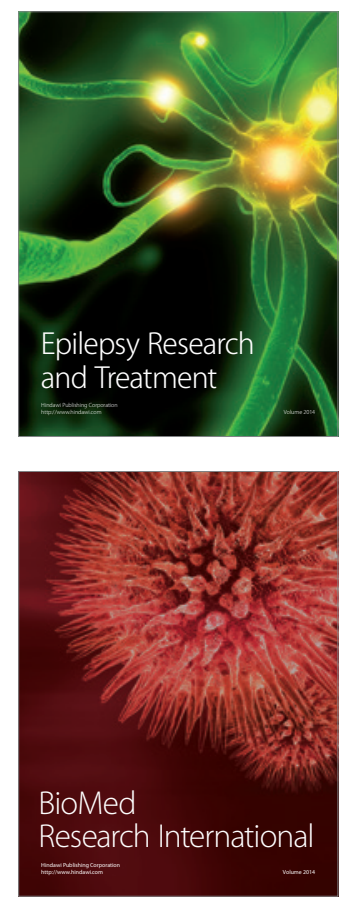

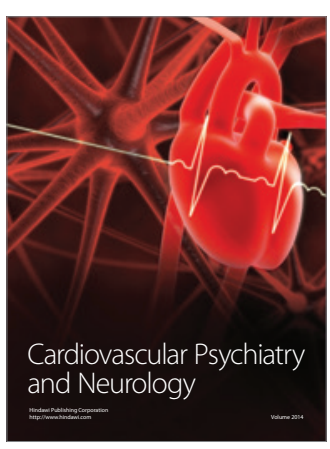

Parkinson's

Disease
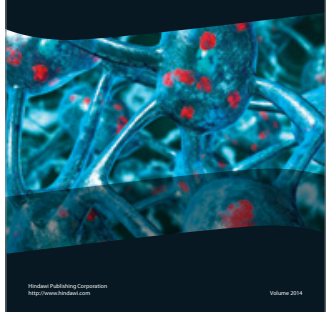